\title{
Lack of correlation between P pulmonale and right atrial overload in chronic obstructive airways disease
}

Shigeru Maeda, Hideki Katsura, Kouji Chida, Tamotu Imai, Kenji Kuboki, Chizuko Watanabe, Kohzui Kida, Shin-ichiro Ohkawa, Satoru Matsushita, Keiji Ueda, Kizuku Kuramoto

\begin{abstract}
The correlation between $P$ pulmonale and right atrial overload in chronic lung disease was studied. Right atrial pressure, pulmonary artery pressure, and cardiac output were measured with a Swan-Ganz catheter in nine patients with chronic lung disease and $P$ pulmonale on the electrocardiogram (P wave amplitude of $\geqslant 2.5 \mathrm{~mm}(0.25 \mathrm{mV})$ in leads II, III, and aVF. The results were compared with those in six patients with an atrial septal defect (left to right shunt $\geqslant 50 \%$ ) and six patients with pulmonary hypertension (mean pressure $\geqslant 30 \mathrm{~mm}$ Hg without left sided heart disease). Right atrial volume and wall thickness were measured in 10 cases of $P$ pulmonale among 1000 necropsy cases and compared with 141 normal hearts from the same series.
\end{abstract}

The patients with $P$ pulmonale did not show a significant increase in right atrial or pulmonary artery pressures. None of the patients with an atrial septal defect or pulmonary hypertension had $P$ pulmonale on the electrocardiogram. In the necropsy cases of $P$ pulmonale mean (1 SD) in right atrial volume $(32$ (12) $\mathrm{ml})$ and wall thickness $(1.5(0.7) \mathrm{mm})$ were not significantly increased $(40(14) \mathrm{ml}$ and $1.4(0.5) \mathrm{mm}$ in the normal hearts). There was a significant inverse relation between the presence of $P$ pulmonale and the cardiothoracic ratio. In all the patients with $P$ pulmonale chest $x$ ray showed a low cardiothoracic ratio, a considerably depressed diaphragm, and a pendulous heart.

This study showed no correlation between $P$ pulmonale and right atrial overload in chronic lung disease. A more vertical anatomical position of the heart, particularly of the right atrium, seems to be the major factor responsible for generation of $\mathbf{P}$ pulmonale in chronic airways disease.

Peaked, tall, and narrow $P$ waves in leads II, III, and aVF in lung disease are called $P$ pulmonale. Though many factors such as verticalisation of the heart, ${ }^{12}$ increased residual volume, ${ }^{3}$ and impaired lung function $^{45}$ have been reported to be correlated with these changes in the $P$ wave, right atrial overload (right atrial enlargement or increased right atrial pressure or both) is still thought to be responsible for $P$ pulmonale in lung disease, especially in cor pulmonale. ${ }^{6}$

Because the relation between haemodynamic function and $P$ wave variables has been little studied we investigated haemodynamic function in patients with chronic obstructive airways disease and the presence of $P$ pulmonale ( $\geqslant 2.5 \mathrm{~mm}$ in leads II, III, and aVF). We compared this with $P$ wave configuration in patients with atrial septal defect and pulmonary hypertension, conditions that increase right atrial volume and pressure respectively, and we studied the correlation between the amplitude of the $P$ waves and the right atrial overload.

\section{Patients and methods \\ PATIENTS}

We studied nine patients with chronic lung disease and $P$ pulmonale between May 1987 and August 1989 at Tokyo Metropolitan Geriatric Hospital. P pulmonale was defined by the following criteria: the amplitude of the $P$ waves in all of leads II, III, and aVF was $\geqslant 2.5 \mathrm{~mm}$ and the duration of the $P$ wave was $\leqslant 0.10 \mathrm{~s}$. As control groups we also studied six patients with atrial septal defect (left to right shunt $\geqslant 50 \%$ ) and six with pulmonary hypertension (mean pressure $\geqslant 30 \mathrm{~mm} \mathrm{Hg}$ ) that was not secondary to left sided heart disease. These conditions increase right atrial volume and pressure respectively. Haemodynamic function was assessed in these two groups at the same hospital between June 1982 and June 1987. Patients with atrial fibrillation were excluded. To evaluate the relation between $P$ pulmonale and right atrial overload we studied 10 patients who met the criteria for $P$ pulmonale (amplitude $\geqslant 0.25 \mathrm{mV}$ in each of lead II, III, and aVF) and 141 patients without any significant clinical findings or cardiac abnormalities at necropsy. These cases came from a consecutive series of 1000 necropsies.

\section{METHODS}

In every patient we measured the right atria and pulmonary artery pressure and cardiac output with a Swan-Ganz catheter and the amplitude and axis of the $P$ waves in the frontal plane to evaluate $P$ wave changes caused by right atrial volume load or pressure load or both. We examined chest radiographs to correlate the cardiothoracic ratio and the shape 
of the heart with the $P$ wave variables. In each group we studied the correlation between the amplitude and axis of the $P$ waves in the frontal plane and indices of haemodynamic function and the cardiothoracic ratio. In the necropsy cases we measured the thickness of the right atrial and ventricular walls and the volume of the right atrium. We used slide calipers to measure the thickness of the right atrial wall at the site of the pectinate muscle and the compact zone of the right ventricular wall $1 \mathrm{~cm}$ below the pulmonary valve. We calculated the right atrial volume by the following formula, assuming that the right atrium was spherical, as previously reported. ${ }^{7}$

$$
\mathrm{RA} \text { volume }=\frac{4 \pi}{3}\left(\frac{\phi \mathrm{RA}+\frac{\mathrm{T}}{\pi}}{2 \pi}\right)^{3}
$$

when $\phi \mathrm{RA}$ is the length of the circle of longitude above the tricuspid valve; $\pi$ is $\mathrm{Pi}$; and $\mathrm{T}$ is the circumference of the tricuspid valve ring. We used the $t$ test to analyse data. A p value of $<0.05$ was regarded as significant.

\section{Results}

P PULMONALE (TABLE 1)

Two patients had chronic obstructive airways disease and seven had old pulmonary tuberculosis. The mean (1 SD) amplitude and axis of the $P$ waves in the frontal plane were $2.79(0.25)$ mm (range $2.50-3.20 \mathrm{~mm}$ ) and $+81(6)^{\circ}$ (range +70 to $+90^{\circ}$ ) respectively. The mean right atrial pressure was normal (2 (2) $\mathrm{mm} \mathrm{Hg}$ ). In the pulmonary artery the systolic pressure was 30 (5) $\mathrm{mm} \mathrm{Hg}$ and the mean pressure was 17 (4) $\mathrm{mm} \mathrm{Hg}$. None of the patients had significant pulmonary hypertension. The cardiac index was normal in all but one patient. Chest radiographs showed a low cardiothoracic ratio (46 (7) \%) (range 35-55\%) in all and even the seven patients with old tuberculosis showed compensatory hyperinflation as well as the constricting changes of the lung caused by tuberculosis. As a result, there was considerable depression of the diaphragm in all. Lung function tests were as follows: vital capacity: 51 (12) \% (range 30-63\%), forced expiratory volume in 1 s 75 (15) \% (range 51-93\%), and oxygen, 71 (18) $\mathrm{mm} \mathrm{Hg}$ (range from 40-93 $\mathrm{mm} \mathrm{Hg}$ ) and carbon dioxide $45(8) \mathrm{mm} \mathrm{Hg}$ (range $32-56 \mathrm{~mm} \mathrm{Hg}$ ) tension in arterial blood.

\section{ATRIAL SEPTAL DEFECT (TABLE 2)}

The chest radiographs and echocardiograms showed considerable dilatation of both the right atrium and ventricle. Mean pulmonary arterial pressure was $26(9) \mathrm{mm} \mathrm{Hg}$ and mean right atrial pressure 4 (3) $\mathrm{mm} \mathrm{Hg}$. The mean amplitude of the $P$ waves in leads II, III, and aVF was $0.96(0.54) \mathrm{mm}$ (range $0.10-1.70 \mathrm{~mm}$ ) and no patient had $P$ pulmonale. The axis of the $P$ waves in the frontal plane was $+65(26)^{\circ}$ (range $+15^{\circ}$ to $+90^{\circ}$ ). In this group the chest radiographs showed considerable cardiomegaly (cardiothoracic ratio $68(3) \%$ ).

PULMONARY HYPERTENSION (TABLE 3)

Mean pulmonary arterial and right atrial pressure were significantly higher $(53(25) \mathrm{mm} \mathrm{Hg}$ and $8(5) \mathrm{mm} \mathrm{Hg}$ respectively) than in patients with $P$ pulmonale. None the less, the mean amplitude of the $P$ waves in leads II, III, and aVF was $0.93(0.42) \mathrm{mm}$, and even the maximal amplitude was only $2.0 \mathrm{~mm}$. No patients in this group had $P$ pulmonale. The axis of the $P$ wave in the frontal plane was $+59(21)^{\circ}$. The cardiac index was low in four patients and normal in

Table 1 Clinical characteristics of the patients with $P$ pulmonale

\begin{tabular}{|c|c|c|c|c|c|c|c|c|c|c|c|}
\hline \multirow[b]{2}{*}{ Case } & \multirow{2}{*}{$\begin{array}{l}\text { Age } \\
(y r)\end{array}$} & \multirow[b]{2}{*}{ Sex } & \multirow{2}{*}{$\begin{array}{l}\text { Underlying } \\
\text { disease }\end{array}$} & \multicolumn{3}{|c|}{$\begin{array}{l}\text { Amplitude of } P \text { waves in } \\
I I, I I I, a V F(\mathrm{~mm})\end{array}$} & \multirow{2}{*}{$\begin{array}{l}P \\
\text { axis }\end{array}$} & \multicolumn{3}{|c|}{ Haemodynamic function } & \multirow{2}{*}{$\begin{array}{l}\text { CTR } \\
(\%)\end{array}$} \\
\hline & & & & Average & Maximum & Minimum & & $P A P(m)$ & $m R A P$ & $C I$ & \\
\hline $\begin{array}{l}1 \\
2 \\
3 \\
4 \\
5 \\
6 \\
6 \\
7 \\
8 \\
9\end{array}$ & $\begin{array}{l}77 \\
72 \\
72 \\
69 \\
72 \\
81 \\
59 \\
59 \\
69\end{array}$ & $\begin{array}{l}\mathbf{M} \\
\mathbf{M} \\
\mathbf{M} \\
\mathbf{F} \\
\mathbf{M} \\
\mathbf{F} \\
\mathbf{M} \\
\mathbf{F} \\
\mathbf{M}\end{array}$ & $\begin{array}{l}\text { COAD } \\
\text { COAD } \\
\text { Old TB } \\
\text { Old TB } \\
\text { Old TB } \\
\text { Old TB } \\
\text { Old TB } \\
\text { Old TB } \\
\text { Old TB }\end{array}$ & $\begin{array}{l}2.93 \\
2 \cdot 66 \\
2.50 \\
2.60 \\
2.70 \\
3.00 \\
3.20 \\
2.53 \\
3.00\end{array}$ & $\begin{array}{l}3 \cdot 0 \\
2 \cdot 8 \\
2.5 \\
2 \cdot 8 \\
2 \cdot 8 \\
3 \cdot 5 \\
3 \cdot 7 \\
2 \cdot 8 \\
3 \cdot 2\end{array}$ & $\begin{array}{l}2 \cdot 8 \\
2.5 \\
2.5 \\
2.5 \\
2.5 \\
2.5 \\
2.6 \\
2.5 \\
2.8\end{array}$ & $\begin{array}{l}+90 \\
+80 \\
+85 \\
+85 \\
+85 \\
+75 \\
+70 \\
+75 \\
+80\end{array}$ & $\begin{array}{l}22 / 6(11) \\
26 / 8(14) \\
28 / 8(15) \\
28 / 10(16) \\
32 / 12(19) \\
38 / 14(22) \\
38 / 18(24) \\
28 / 8(15) \\
34 / 12(19)\end{array}$ & $\begin{array}{l}0 \\
6 \\
0 \\
2 \\
1 \\
1 \\
5 \\
1 \\
3\end{array}$ & $\begin{array}{l}2 \cdot 26 \\
3 \cdot 28 \\
2 \cdot 07 \\
3 \cdot 81 \\
2 \cdot 80 \\
3.30 \\
3 \cdot 41 \\
2 \cdot 27 \\
2 \cdot 30\end{array}$ & $\begin{array}{l}42 \\
51 \\
37 \\
53 \\
52 \\
48 \\
41 \\
55 \\
35\end{array}$ \\
\hline
\end{tabular}

$\mathrm{CI}$, cardiac index $\left(1 / \mathrm{min} / \mathrm{m}^{2}\right)$; COAD, chronic obstructive airways disease; CTR, cardiothoracic ratio; $\mathrm{mRAP}$, mean right atrial pressure $(\mathrm{mm} \mathrm{Hg})$; TB, pulmonary tuberculosis; PAP $(\mathrm{m})$, pulmonary artery pressure (mean) (mm $\mathbf{H g})$.

Table 2 Clinical characteristics of patients with an atrial septal defect

\begin{tabular}{|c|c|c|c|c|c|c|c|c|c|c|}
\hline \multirow[b]{2}{*}{ Case } & \multirow{2}{*}{$\begin{array}{l}\text { Age } \\
(y r)\end{array}$} & \multirow[b]{2}{*}{ Sex } & \multicolumn{3}{|c|}{$\begin{array}{l}\text { Amplitude of } P \text { waves in } \\
I I, I I I, a V F(\mathrm{~mm})\end{array}$} & \multirow[b]{2}{*}{$P$ axis } & \multicolumn{3}{|c|}{ Haemodynamic function } & \multirow[b]{2}{*}{ CTR (\%) } \\
\hline & & & Average & Maximum & Minimum & & $P A P(m)$ & $m R A P$ & $L \rightarrow R$ shunt (\%) & \\
\hline $\begin{array}{l}1 \\
2 \\
3 \\
4 \\
5 \\
6\end{array}$ & $\begin{array}{l}71 \\
56 \\
62 \\
71 \\
70 \\
78\end{array}$ & $\begin{array}{l}\mathbf{F} \\
\mathbf{F} \\
\mathbf{F} \\
\mathbf{F} \\
\mathbf{F} \\
\mathbf{M}\end{array}$ & $\begin{array}{l}0.67 \\
0.97 \\
1.03 \\
0.10 \\
1.27 \\
1.70\end{array}$ & $\begin{array}{l}1.0 \\
1.1 \\
1.3 \\
0.1 \\
1.5 \\
1.9\end{array}$ & $\begin{array}{l}0.3 \\
0.7 \\
0.5 \\
0.1 \\
1.0 \\
1.4\end{array}$ & $\begin{array}{l}+75 \\
+90 \\
+60 \\
+15 \\
+75 \\
+75\end{array}$ & $\begin{array}{l}46 / 18(27) \\
42 / 18(26) \\
29 / 7(14) \\
67 / 23(38) \\
35 / 10(18) \\
40 / 15(33)\end{array}$ & $\begin{array}{l}4 \\
2 \\
0 \\
5 \\
4 \\
8\end{array}$ & $\begin{array}{l}68 \\
74 \\
50 \\
68 \\
60 \\
71\end{array}$ & $\begin{array}{l}63 \\
67 \\
71 \\
72 \\
66 \\
69\end{array}$ \\
\hline
\end{tabular}

$\mathrm{L} \rightarrow \mathbf{R}$, left to right. See footnote to table 1 for other abbreviations. 
Table 3 Clinical characteristics of patients with pulmonary hypertension

\begin{tabular}{|c|c|c|c|c|c|c|c|c|c|c|c|}
\hline \multirow[b]{2}{*}{ Case } & \multirow[b]{2}{*}{$\begin{array}{l}\text { Age } \\
(y r)\end{array}$} & \multirow[b]{2}{*}{ Sex } & \multirow[b]{2}{*}{$\begin{array}{l}\text { Underlying } \\
\text { disease }\end{array}$} & \multicolumn{3}{|c|}{$\begin{array}{l}\text { Amplitude of } P \text { waves in } \\
I I, I I I, a V F(\mathrm{~mm})\end{array}$} & \multirow[b]{2}{*}{$\begin{array}{l}P \\
\text { axis }\end{array}$} & \multicolumn{3}{|c|}{ Haemodynamic function } & \multirow[b]{2}{*}{$\begin{array}{l}\text { CTR } \\
(\%)\end{array}$} \\
\hline & & & & Average & Maximum & Minimum & & $P A P(m)$ & $m R A P$ & $C I$ & \\
\hline $\begin{array}{l}1 \\
2 \\
3 \\
4 \\
5 \\
6\end{array}$ & $\begin{array}{l}79 \\
87 \\
77 \\
52 \\
73 \\
81\end{array}$ & $\begin{array}{l}\mathbf{F} \\
\mathbf{M} \\
\mathbf{F} \\
\mathbf{M} \\
\mathbf{M} \\
\mathbf{F}\end{array}$ & $\begin{array}{l}\text { PTE } \\
\text { COAD } \\
\text { PTE } \\
\text { PTE } \\
\text { PTE } \\
\text { PTE }\end{array}$ & $\begin{array}{l}0.73 \\
1.43 \\
0.67 \\
0.60 \\
1.50 \\
0.63\end{array}$ & $\begin{array}{l}0.8 \\
1.5 \\
0.9 \\
1.0 \\
2.0 \\
1.0\end{array}$ & $\begin{array}{l}0.6 \\
1 \cdot 3 \\
0 \cdot 3 \\
0 \cdot 3 \\
0 \cdot 8 \\
0.4\end{array}$ & $\begin{array}{l}+75 \\
+90 \\
+60 \\
+30 \\
+55 \\
+45\end{array}$ & $\begin{array}{r}88 / 20(43) \\
54 / 24(34) \\
52 / 31(38) \\
148 / 67(94) \\
110 / 55(73) \\
70 / 15(35)\end{array}$ & $\begin{array}{r}6 \\
3 \\
15 \\
14 \\
4 \\
5\end{array}$ & $\begin{array}{l}1 \cdot 48 \\
2 \cdot 40 \\
2 \cdot 20 \\
1.50 \\
2 \cdot 72 \\
1 \cdot 86\end{array}$ & $\begin{array}{l}67 \\
43 \\
71 \\
58 \\
53 \\
59\end{array}$ \\
\hline
\end{tabular}

PTE, pulmonary thromboembolism. See footnote to table 1 for other abbreviations.

Table 4 Clinical characteristics and findings at necropsy in 10 patients with $P$ pulmonale

\begin{tabular}{|c|c|c|c|c|c|c|c|c|}
\hline \multirow[b]{2}{*}{ Case } & \multirow{2}{*}{$\begin{array}{l}\text { Age } \\
(y r)\end{array}$} & \multirow[b]{2}{*}{ Sex } & \multirow{2}{*}{$\begin{array}{l}\text { Underlying } \\
\text { disease }\end{array}$} & \multirow{2}{*}{$\begin{array}{l}\text { Mean amplitude of } \\
P \text { waves }(I I, I I I, a V F) \\
(\mathrm{mm})\end{array}$} & \multicolumn{2}{|l|}{ Right atrium } & \multirow{2}{*}{$\frac{\text { Right ventricle }}{\text { Thickness (mm) }}$} & \multirow[b]{2}{*}{ CTR $(\%$} \\
\hline & & & & & Volume (ml) & Thickness & & \\
\hline $\begin{array}{l}1 \\
2 \\
3 \\
4 \\
5 \\
6 \\
7 \\
8 \\
9 \\
10\end{array}$ & $\begin{array}{l}82 \\
79 \\
88 \\
65 \\
78 \\
73 \\
71 \\
84 \\
74 \\
85\end{array}$ & $\begin{array}{l}\mathbf{M} \\
\mathbf{F} \\
\mathbf{M} \\
\mathbf{M} \\
\mathbf{F} \\
\mathbf{M} \\
\mathbf{M} \\
\mathbf{M} \\
\mathbf{M} \\
\mathbf{F}\end{array}$ & $\begin{array}{l}\text { COAD } \\
\text { COAD } \\
\text { COAD } \\
\text { COAD } \\
\text { COAD } \\
\text { COAD } \\
\text { COAD } \\
\text { Old TB } \\
\text { Old TB } \\
\text { None }\end{array}$ & $\begin{array}{l}2 \cdot 83 \\
2 \cdot 80 \\
3 \cdot 17 \\
2.57 \\
2.50 \\
2 \cdot 67 \\
3.33 \\
2.93 \\
2.77 \\
2 \cdot 87\end{array}$ & $\begin{array}{l}36 \\
15 \\
36 \\
23 \\
43 \\
22 \\
33 \\
43 \\
51 \\
21\end{array}$ & $\begin{array}{l}1 \cdot 1 \\
1.0 \\
3.0 \\
1.2 \\
2.3 \\
1.2 \\
1.0 \\
1.0 \\
1.6 \\
1.2\end{array}$ & $\begin{array}{l}2 \cdot 5 \\
2 \cdot 2 \\
3 \cdot 0 \\
4 \cdot 0 \\
5 \cdot 8 \\
4 \cdot 0 \\
2 \cdot 5 \\
4 \cdot 0 \\
1.8 \\
3.0\end{array}$ & $\begin{array}{l}44 \\
52 \\
45 \\
39 \\
46 \\
36 \\
43 \\
46 \\
49 \\
44\end{array}$ \\
\hline \multicolumn{4}{|c|}{$\begin{array}{l}\text { Mean } 1 \text { SD } \\
\text { Necropsy cases with normal heart }\end{array}$} & $\begin{array}{l}2 \cdot 84(0 \cdot 25) \\
(\mathrm{n}=141)\end{array}$ & $\begin{array}{l}32(12) \\
40(14)\end{array}$ & $\begin{array}{l}1.5(0) \\
1.4(0.5)\end{array}$ & $\begin{array}{l}3 \cdot 3(1 \cdot 2) \\
3 \cdot 8(1 \cdot 2)\end{array}$ & $\begin{array}{l}44(5)^{\star} \\
53(7)^{\star}\end{array}$ \\
\hline
\end{tabular}

$\star \mathrm{P}<0 \cdot 01$. See footnote to table 1 for abbreviations.

Table 5 Clinical (mean (1SD)) characteristics of each group

\begin{tabular}{|c|c|c|c|c|c|c|}
\hline & \multirow{2}{*}{$\begin{array}{l}\text { P pulmonale } \\
\text { (group 1) } \\
(n=9)\end{array}$} & \multirow{2}{*}{$\begin{array}{l}\operatorname{ASD} \\
(\text { group } 2) \\
(n=6)\end{array}$} & \multirow{2}{*}{$\begin{array}{l}P H \\
\text { (group 3) } \\
(n=6)\end{array}$} & \multicolumn{3}{|c|}{ p Value } \\
\hline & & & & $1 v 2$ & $1 v 3$ & $2 v 3$ \\
\hline $\begin{array}{l}\text { Age (yr) } \\
\operatorname{Sex}(F / M)\end{array}$ & $\begin{array}{l}70 \cdot 0(7 \cdot 3) \\
3 / 6\end{array}$ & $\begin{array}{l}68 \cdot 0(7 \cdot 8) \\
5 / 1\end{array}$ & $\begin{array}{l}74 \cdot 8(12 \cdot 1) \\
3 / 3\end{array}$ & NS & NS & NS \\
\hline $\begin{array}{l}\text { P waves } \\
\text { Mean amplitude } \\
\text { Axis }\left({ }^{\circ}\right)\end{array}$ & $\begin{array}{l}2 \cdot 79(0 \cdot 25) \\
+81(6)\end{array}$ & $\begin{array}{l}0.96(0.54) \\
+65(26)\end{array}$ & $\begin{array}{l}0.93(0.42) \\
+59(21)\end{array}$ & $\begin{array}{l}0.01 \\
\text { NS }\end{array}$ & $\begin{array}{l}0.01 \\
0.05\end{array}$ & $\begin{array}{l}\text { NS } \\
\text { NS }\end{array}$ \\
\hline $\begin{array}{l}\text { Pressure data }(\mathrm{mm} \mathrm{Hg}) \\
\text { mPAP } \\
\text { mRAP } \\
\text { CI }\left(1 / \mathrm{min} / \mathrm{m}^{2}\right) \\
\text { CTR }(\%)\end{array}$ & $\begin{array}{l}17(2) \\
2(2) \\
2.83(0.63) \\
46(7)\end{array}$ & $\begin{array}{r}26(9) \\
4(3) \\
68(3)\end{array}$ & $\begin{array}{l}53(25) \\
8(5) \\
2 \cdot 03(0 \cdot 50) \\
59(10)\end{array}$ & $\begin{array}{l}\text { NS } \\
\text { NS } \\
0.01\end{array}$ & $\begin{array}{l}0.05 \\
0.05 \\
0.05 \\
0.05\end{array}$ & $\begin{array}{l}0 \cdot 05 \\
\text { NS } \\
\text { NS }\end{array}$ \\
\hline
\end{tabular}

^Mean amplitude in leads II, III, and aVF (mm).

ASD, atrial septal defect; $\mathrm{PH}$, pulmonary hypertension. See footnote to table 1 for other abbreviations.

two. The chest radiographs showed moderate cardiomegaly (cardiothoracic ratio $59(10) \%$ ).

NECROPSY FINDINGS IN 10 PATIENTS WITH P PULMONALE (TABLE 4)

The average amplitude of the $P$ waves in leads II, III, and aVF was $2 \cdot 84(0 \cdot 25) \mathrm{mm}$ in patients with $P$ pulmonale and $0.63(0.41) \mathrm{mm}$ in 141 patients with normal hearts $(p<0.01)$. Right atrial volume and wall thickness were similar in patients with $P$ pulmonale and in controls $(32$ (12) $\mathrm{ml} v 44(5) \mathrm{ml} ; 1.5(0.7) \mathrm{mm} v 1.4(0.5) \mathrm{mm}$ respectively) as was the thickness of the right ventricle $(3.3(1.2) v 3.8(1.2) \mathrm{mm})$. The chest radiographs of all patients with $\mathrm{P}$ pulmonale showed that the cardiothoracic ratio (44 (5) \%) was significantly smaller than in the controls (53 (7) $\%, p<0.01$ ) and that the heart was pendulous.

Table 5 shows the data for each of the groups.

\section{Discussion}

Peaked, tall, and narrow $P$ waves in leads II, III, and aVF are accepted criteria for $P$ pulmonale, but these features have no quantitative definition. Controversy about the implication of $P$ pulmonale may derive from its ambiguous definition. We selected patients with chronic airways disease who had very tall $P$ waves ( $\geqslant$ $2.5 \mathrm{~mm}$ ) in each of leads II, III, and aVF. In this group with $\mathbf{P}$ pulmonale, none of the

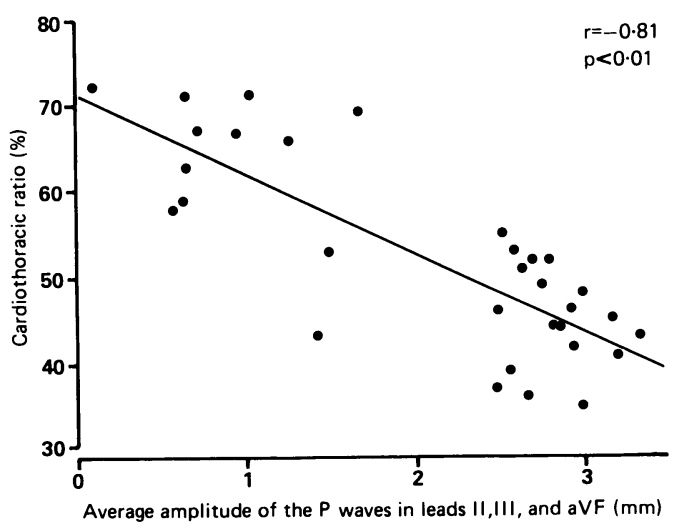

Figure 1 Relation between the mean amplitude of the $P$ waves in leads II, III, and $a V F$ and the cardiothoracic ratio. 
Figure 2 Chest radiographs in patients with $P$ pulmonale. Posteroanterior views $(A)$ and lateral views $(B)$ showing straightened right and posterior cardiac borders respectively. There was no significant enlargement of the right atrium. Both views also show appreciable depression of the diaphragm.
(A)
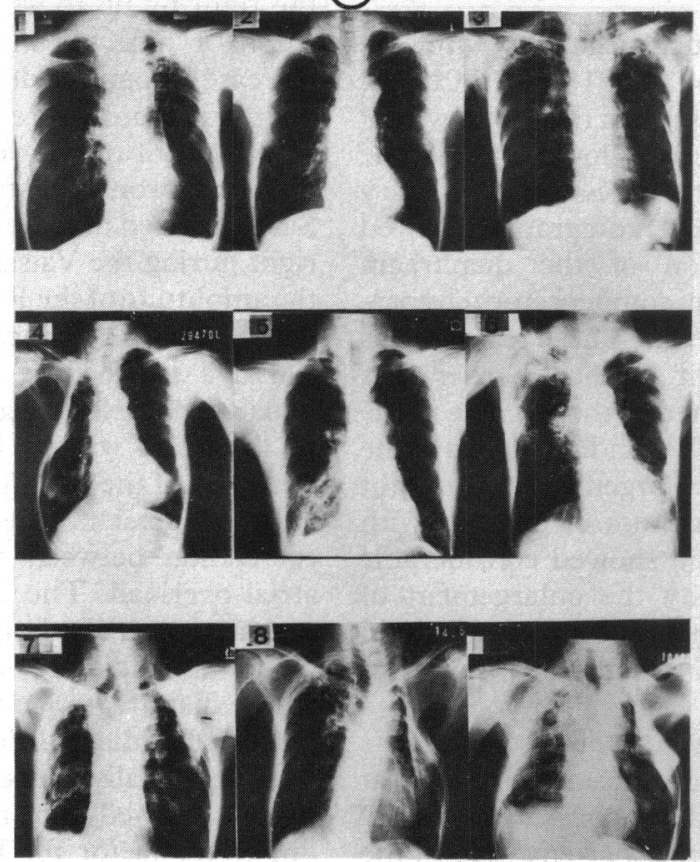

patients showed significant increase in the right atrial or pulmonary artery pressure, and in eight of the nine patients cardiac output was normal. In contrast, none of the patients with atrial septal defects (which load the right atrium and right ventricle with increased volume) or with pulmonary hypertension (which loads the right atrium and ventricle with increased pressure) had $\mathrm{P}$ pulmonale. At necropsy 10 patients with $P$ pulmonale showed no evidence of right atrial overload compared with the normal hearts; though in two patients there was hypertrophy of the pectinate muscle of the right atrium. Caird and Wilcken also found little correlation between $P$ pulmonale and anatomical abnormality of the right atrium. ${ }^{3}$ Saha reported that right atrial enlargement or increased right atrial pressure on both are important factors for the change of the $P$ waves in cor pulmonale, in addition to the

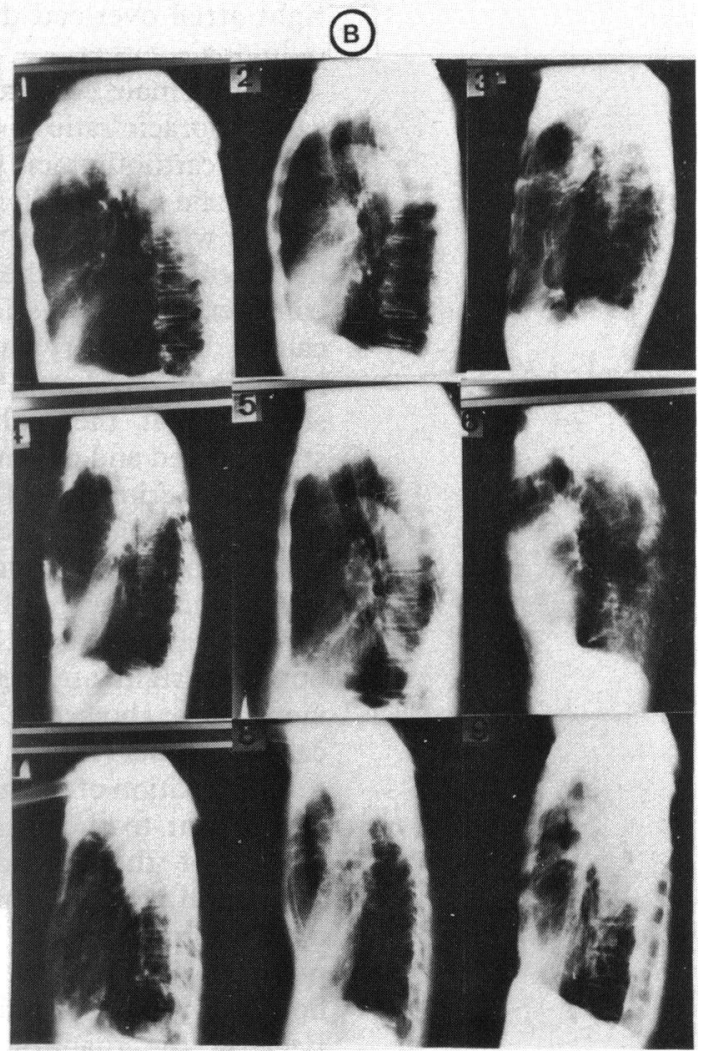

combination of tachycardia, increased residual volume, and increased intrathoracic pressure. ${ }^{6}$ There were no patients with $P$ pulmonale in our group of patients with pulmonary hypertension-the disease most likely to cause cor pulmonale. None of the patients with atrial septal defect showed $\mathrm{P}$ pulmonale, despite the right atrial enlargement caused by volume overload. So we found no correlation between $P$ pulmonale and right atrial enlargement or increased right atrial pressure.

Spodick $e t$ al found that the shift of the $P$ axis to the right as well as increased $P$ wave amplitude was associated with appreciable impaired lung function. ${ }^{4}$ All our patients with $P$ pulmonale also showed impaired lung function. Almost all of them, however, showed normal haemodynamic function. Our data showed that impaired lung function did not always correlate with right atrial overload, and
Figure 3 Relation between the right atrium and the diaphragm showing the direction of the $P$ vector in the frontal plane and the amplitude of the $P$ waves reflected to the leads in the frontal plane $(I, I I, I I I, a V F)$ when the $P$ vector showed maximum intensity. $(A)$ Normal relation. $(B)$ When the diaphragm is depressed. SVC, superior vena cava; IVC, inferior vena cava; $S N$, sinus node; $H V$, hepatic vein;

$T V$, tricuspid valve; -, heart muscle depolarised; + , heart muscle at resting membrane potential.
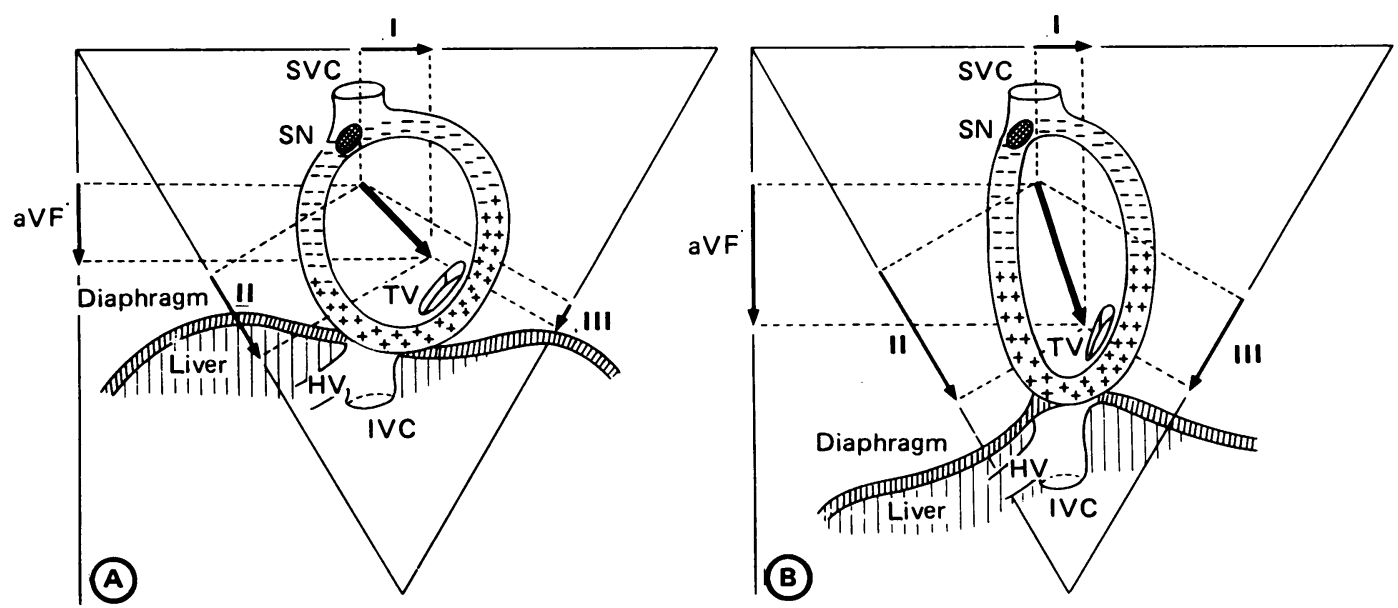
right atrial overload did not correlate with $\mathbf{P}$ pulmonale, either.

$P$ pulmonale correlated negatively with the cardiothoracic ratio $(r=-0.81, p<0.01)$ (fig 1). The cardiothoracic ratio in the group with $P$ pulmonale was significantly lower than in the groups with atrial septal defect or pulmonary hypertension and chest radiographs showed considerable depression of the diaphragm caused by primary or compensatory hyperinflation of the lungs. The chest radiographs showed that the right cardiac border was straightened and deviated to the left side in the posteroanterior view. This finding indicated the absence of significant enlargement of the right atrium compared with those of patients with atrial septal defect, who showed considerable cardiomegaly caused by the enlargement of both the right atrium and ventricle. Lateral views also showed a straightened posterior cardiac border (fig 2).

The position of the heart is determined by its attachment to the mediastinum by the great vessels of the ascending aorta, pulmonary artery and vein, and superior vena cava in the upper portion and by the pericardium in the posterior portion. The lower part of the heart, however, is fixed by only the inferior vena cava. Because the diaphragm was depressed the inferior vena cava was displaced inferiorly and the right atrium was stretched between the superior and inferior venae cavae and was extended vertically (fig 3 ). In the atrium an impulse formed in the sinus node spreads radically along the wall unlike in the ventricle where it is conducted from the endocardium toward the epicardium. The direction of the maximum $P$ wave vector in sinus rhythm is then usually down towards the left and anteriorly or posteriorly. Because the right atrium was stretched and extended between the superior and inferior venae cavae, the direction of the $\mathbf{P}$ wave vector shifted rightward by almost $90^{\circ}$ (fig 3). All our patients with $P$ pulmonale showed rightward shift of the $P$ wave axis. Juan et al also reported that $56 \%$ of patients (96/171) with chronic obstructive airways disease had a shift of $\geqslant+70^{\circ}$ in the $P$ wave axis, but only one patient had a shift of $>+90^{\circ} .{ }^{5}$ When the maximum $P$ vector shifts to the right by up to $90^{\circ}$, the components of the $P$ vector reflected in leads II, III, and aVF increase in amplitude. This seemed to be the main mechanism responsible for increased amplitude of the $P$ waves in leads II, III, and aVF in chronic obstructive airways disease. Saha reported that the $P$ axis moved toward the right during the Valsalva manoeuvre, and that the amplitude of the P waves in leads II and III was considerably increased both during the Valsalva manoeuvre and deep inspiration. ${ }^{6}$ Saha's report also suggested that verticalisation of the heart was an important factor in the changing of the amplitude and axis of $P$ waves.

In conclusion, there seemed to be little correlation between $\mathbf{P}$ pulmonale and right atrial overload. The chest radiographs of the patients with $\mathbf{P}$ pulmonale showed a low cardiothoracic ratio, considerable depression of the diaphragm, and straightened right and posterior cardiac borders. Verticalisation of the heart, especially vertical extension of the right atrium, seemed to be a more likely and a more important factor for $\mathbf{P}$ pulmonale in chronic obstructive airways disease than the haemodynamic effect of impaired lung function on the right atrium.

1 Zuckermann R, Cabrera E, Fishleder BL, Sodi-Pallares D. Electrocardiograms in chronic cor pulmonale. Am Heart 1948;35:421-37.

2 Wasserburger RH, Kelly JR, Rasmussen BS, John HJ. The electrocardiographic pentalogy of pulmonary emphysema; a correlation of roentgenographic findings and pulmonary function studies. Circulation 1969;20: $831-41$

3 Caird FI, Wilcken DEL. The electrocardiogram in chronic bronchitis with generalized obstructive lung disease; its relation to ventilatory function. Am J Cardiol 1962;10 5-13.

4 Spodick DH, Hauger-Klevene JH, Tyler JM, Muench $\mathrm{H}$ Dorr CA. The electrocardiogram in pulmonary emphysema; relationship of characteristic electrocardiographic findings to severity of disease as measured by the degree of airway obstruction. Am Rev Respir Dis 1963;88:14-9.

5 Juan BC, Jose MA, Nguyen BK, William WS, Harold MS $P$ wave changes in chronic obstructive pulmonary disease. Am Heart $J$ 1970;79:444-53.

6 Saha NC. Study of the $\mathrm{P}$ wave in normal and obstructive lung disease in Delhi. Am Heart J 1970;80:154-61.

7 Sugiura M, Okada $R$, Iizuka $H$, et al. Clinicopathological studies on normality in the aged heart. Jpn J Geria 1969;6:297-307. 